Mujahed T. Qasim B.D.S, H.D.D.

Munther N. Kazanji B.D.S , M.Sc. (Asst. Prof)

\section{The Effect of Two Denture Adhesives on Maxillary Complete Denture Dislodgement. A Pilot Study}

Post graduate student/Prosthetic Department College of Dentistry, University of Mosul

Senior Prosthodontics/ ProstheticDepartment College of Dentistry, University of Mosul

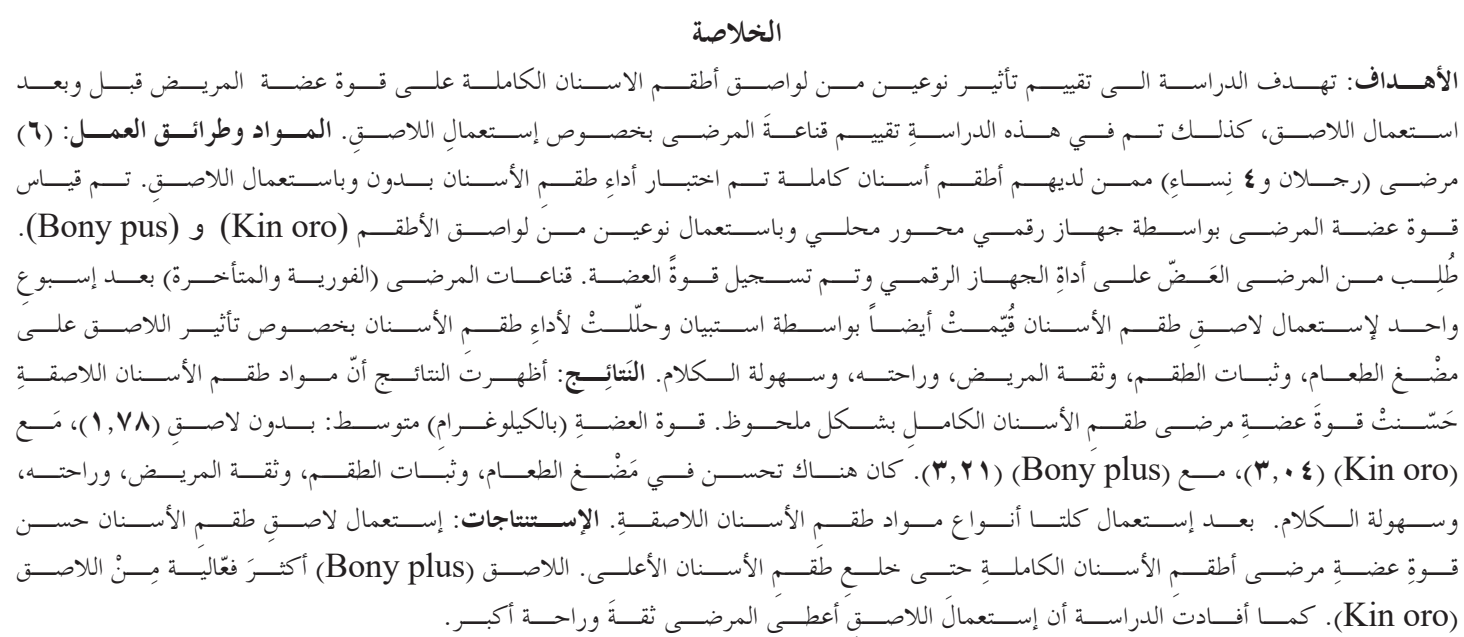

ABSTRACT

Aim: The purpose of this study was to evaluate the effect of two denture adhesives on incisal bite force until denture dislodgement without and with the adhesive. This in-practice study assessed also patients' perception regarding the use of adhesive. Materials and Methods: A total of 6 patients ( 2 men, 4 women) who wore complete maxillary and mandibular dentures were tested for denture performance both without and with denture adhesive. A locally constructed digital biting force device was used to measure the incisal bite force. Two adhesives pastes (Kin oro and Bony plus) were used in the study. Patients were asked to bite on the digital biting force device and the readings of incisal bite force were recorded. Patient perceptions (instant perception and delayed perception) after 1 week of using the denture adhesive were also assessed by a questionnaire and analyzed for denture performance on chewing and mastication, retention and fitness, confidence, comfort, and speaking. Results: The result showed that denture adhesives improved the incisal bite force of complete denture wearers significantly. The incisal bite force (in $\mathrm{kg}$ ) (mean : without adhesive 1.78, with Kin oro 3.04, and with Bony plus 3.21). There was an improvement in chewing and mastication, retention and fitness, confidence, comfort, and speaking after using both types of denture adhesives. Conclusions: The use of denture adhesive was found to be significantly effective in improving the incisal bite force of complete dentures until the dislodgement of upper denture. Bony plus paste adhesive was found to be more effective than Kin oro paste. Subjectively, the patients reported an improved perception of denture performance and that the use of adhesive provided greater confidence when using the prosthesis.

Key words: Denture Adhesive, Bite Force.

Effect of Denture Adhesives on Denture Dislodgement. Al-Rafidain Dent J.; Al-Rafidain Dent J. 2015; 15(1): 381-386.

Received: $16 / 5 / 2013$

Sent to Referees: $12 / 6 / 2013$

Accepted for Publication: 14/8/2013

\section{INTRODUCTION}

Improving denture retention and stability is of significant interest in prosthodontics. ${ }^{(1,2)}$ Approaches to this challenge include the use of over dentures, implant-retained dentures, and denture adhesives. The selection of the overdenture or implant option is dependent upon many considerations, which are beyond the scope of this manuscript. Millions of denture wearers, however, use denture adhesives as an over-the counter remedy and these products are recommended by many professionals. In the past, denture adhesives were viewed as useful for patients

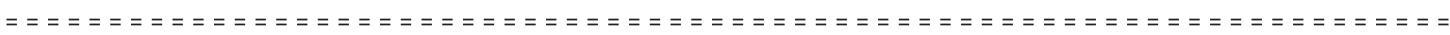


with ill-fitting dentures. Today, however, this conventional perspective is being challenged. Research has demonstrated that denture patients using adhesives masticate in a similar fashion to patients who have natural teeth. ${ }^{(2)}$ Clinical indications for the use of denture adhesives are the complicated anatomic conditions (atrophic, hard denture bearing area), making the new denture more easily acceptable, psychological factors, neurological disorders or limited salivation ${ }^{(3)}$

Objective improvement of retention of dentures using denture adhesives has been demonstrated by in vitro tests. ${ }^{(1,4)}$ Many clinical studies were conducted to evaluate whether the adhesives used to improve complete denture retention are truly effective and able to increase denture adhesion to the mucosa covering the edentulous alveolar ridge, and to evaluate the extent to which complete maxillary and mandibular dentures move during chewing and mastication ${ }^{(5-8)}$. Many other clinical studies were conducted to determine and assess the effect of different type of denture adhesives on the incisal bite force of complete denture wearers until the dislodgement of upper denture, using a disposable gnathometer, ${ }^{(2,9-13)}$ gnathodynamometry, ${ }^{(14,15)}$ and pressure transducer. ${ }^{(16)}$

The purpose of this study was to evaluate the efficacy of two different denture adhesives on the retention of upper complete denture by measuring the incisal bite force without and with the denture adhesives using a locally constructed digital biting force measurement device, and to correlate between the efficacy of the both types of denture adhesives. In addition to that to assess the instant and delayed (after 12 hours) patient perception by a questionnaire in regarding to chewing and mastication, retention and fitness, confidence, comfort, and speaking.

\section{MATERIALS AND METHODS}

A total of 6 patients (2 men, 4 women) with mean age of 65 years old who wore complete maxillary and mandibular dentures. The study was approved by the Ethics Committee of the Faculty of Dentistry. Inclusion criteria were: conventional maxillary and mandibular complete dentures worn for at least 1 year; demonstrating good acceptance of complete denture treatment following a standard period of adaptation and adjustment; not being a denture adhesive user; no known allergy to denture adhesive; no any uncontrolled medical problem, and no any oral condition that might interfere with the research. ${ }^{(14)}$ The maximum incisal bite force of the complete dentures was assessed without and with application of the denture adhesive, using a locally constructed digital biting force measurement device which record the incisal bite force in $\mathrm{Kg}$. An electronic kitchen scale (SF-400, China) was modified by an experience technologist. He took the sensor bar outside the electronic scale and join it to a thin metallic foil to be more suitable to use as a sensor biting bar by the patient during study (Figure 1).

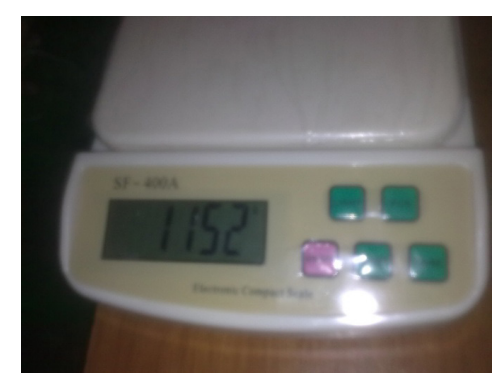

Figure (1) : A locally constructed digital biting force measurement device.

The device was placed between the upper and lower central incisors. Each patient was instructed to bite hard on the allocated area (Figure 2) until the maxillary denture dislodged at the posterior palatal seal, and the resulting value was recorded. 

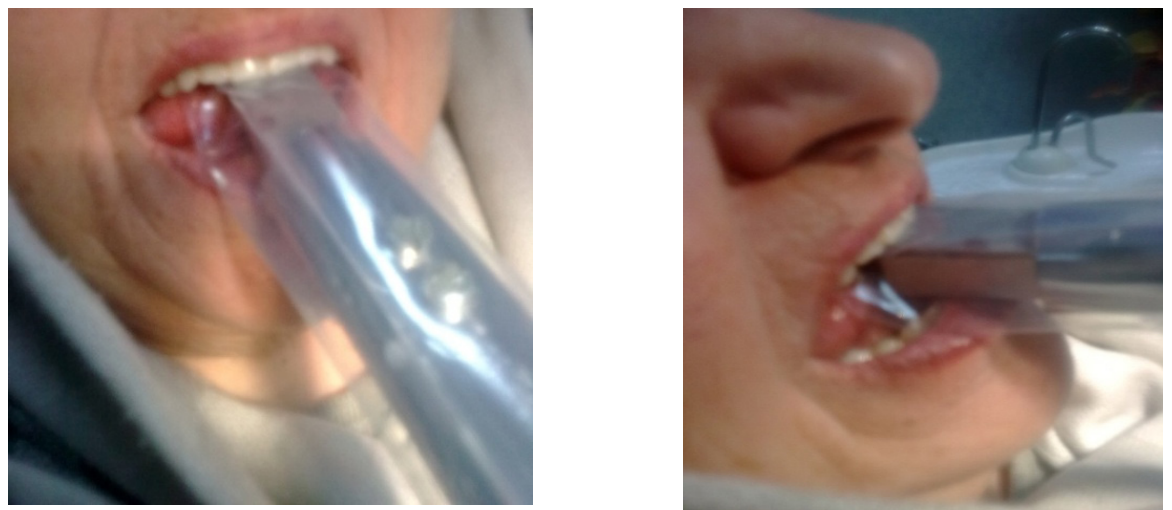

Figure (2) : Incisal biting of patient on device between upper and lower central incisors.

The procedure was repeated 3 times, both without and with application of the two types of denture adhesive pastes (Kin oro, Spain) and (Bony plus, Switzerland) (Figure 3), and the average score was recorded. (2)

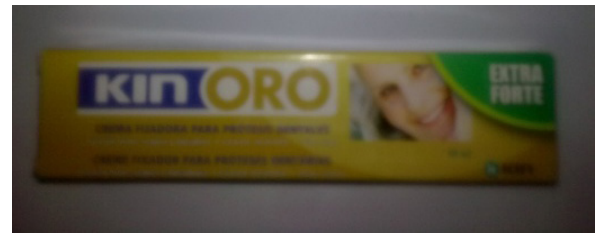

Figure (3) : The two types of denture adhesives used in the study.

The same amount of adhesive was used in all tests, distributing the material in three equivalent portions in the anterior and lateral

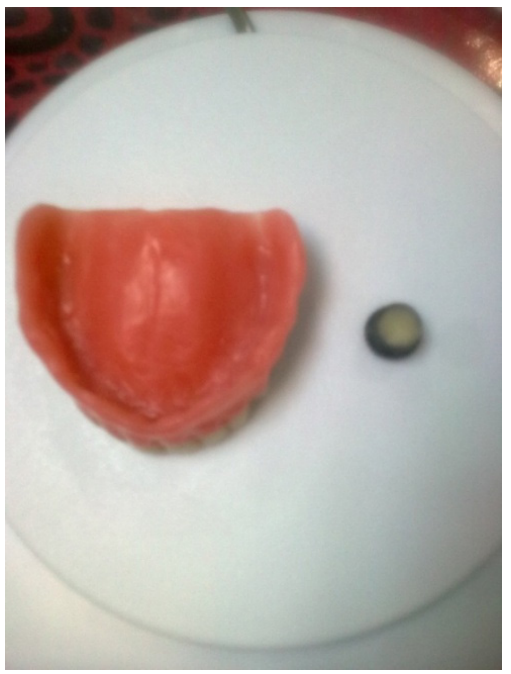

zones, in compliance with the instructions of the manufacturers (Figure 4).

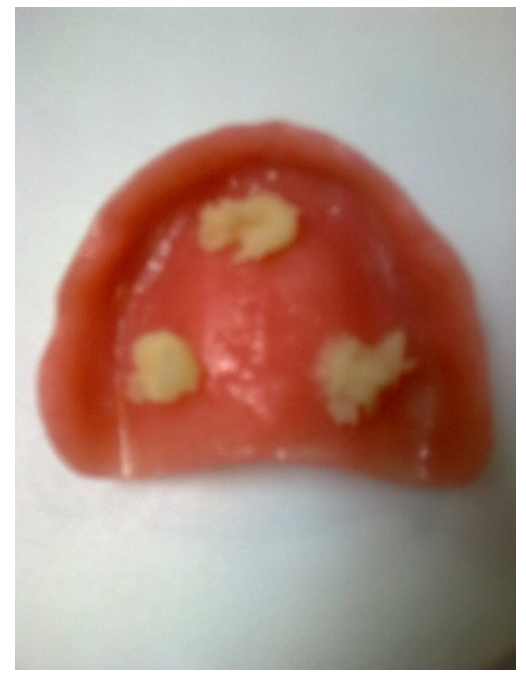

Figure (4) :The same amount of adhesive was used in all tests.

Patient perceptions (instant perception and delayed perception) after 1 week of using the denture adhesive were also assessed by a questionnaire and analyzed for denture performance as well as the effects on chewing and mastication, retention and fitness, confidence, comfort, and speaking. ${ }^{(2)}$

\section{RESULTS}

Mean and Standard deviations of recorded incisal bite force (in $\mathrm{kg}$ ) of all patients (without using denture adhesives and with using two types of denture adhesives) are shown in (Table 1) and (Figure 5). 
Qasim MT, Kazanji MN

Table (1) : The mean of the bite force measurements of all patients.*

\begin{tabular}{cccccc}
\hline Method & Patient No. & Minimum value & Maximum value & Mean & SD $^{* *}$ \\
\hline Control & 6 & 1.07 & 2.69 & 1.78 & 0.76 \\
Kin oro & 6 & 1.46 & 4.30 & 3.04 & 1.25 \\
Bony plus & 6 & 1.64 & 4.50 & 3.21 & 1.18 \\
\hline
\end{tabular}

* All measurements in Kg

** $\mathrm{SD}=$ Standard Deviation

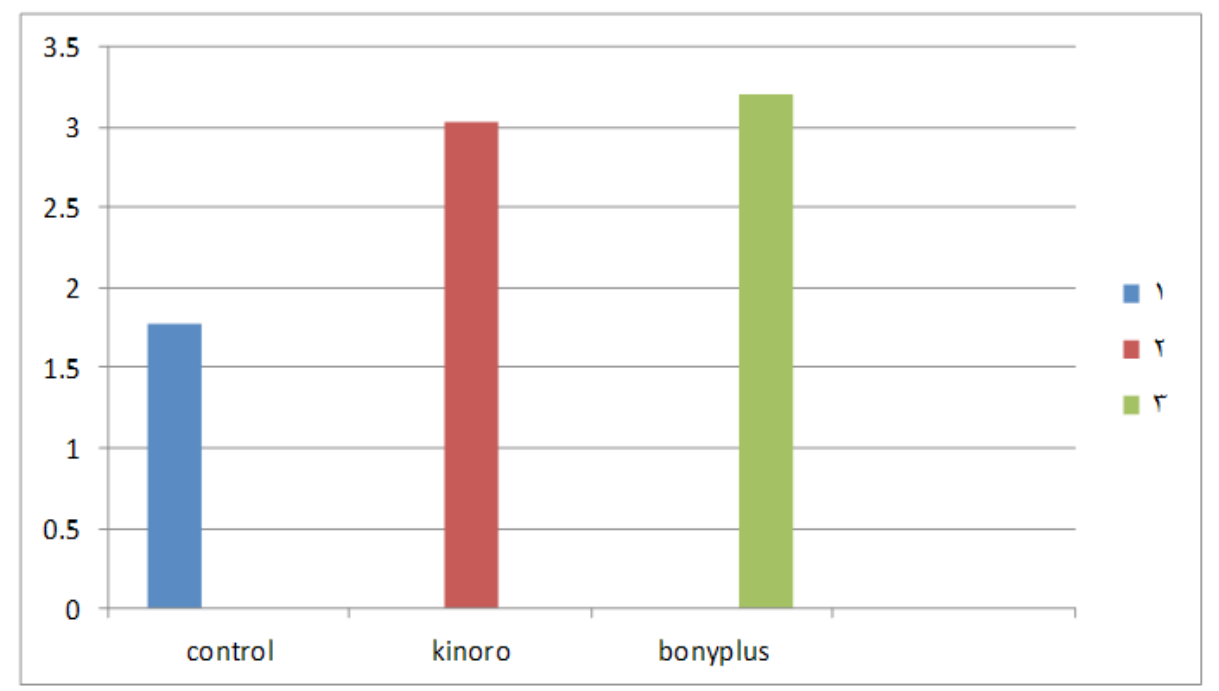

Figure (5) : The mean of the bite force measurements of all patients.*

* All measurements in $\mathrm{Kg}$

From statistical analysis a significant at $\mathrm{P} \leq 0.05$ difference was found among the complete denture wearers without application of adhesives and with application of the two types of adhesives using t-test (Table 2).

Table (2) : The student t-test of kinoro and Bonyplus denture adhesives.

\begin{tabular}{cccc}
\hline Method & Patient No. & t- value & significance \\
\hline Control versus kinoro & 6 & $-4.99-$ & $0.004^{*}$ \\
Control versus bonyplus & 6 & $-6.28-$ & $0.002^{*}$ \\
Kinoro versus bonyplus & 6 & $-2.57-$ & $0.05^{*}$ \\
\hline
\end{tabular}

* Significance

Bony plus adhesive was found to be significantly more effective than Kin oro adhesive. For the analysis of the patients' perceptions (Table 3) and (Figure 6), there was an improvement in instant perception for both types of denture adhesive in regarding chewing and mastication, retention and fitness, confidence, comfort, and speaking except for comfort with using Bony plus adhesive. 
Table (3) : Analysis of variance (ANOVA) for comparison of color change $\Delta \mathrm{E}$ among different types of beverage

\begin{tabular}{|c|c|c|c|c|c|c|c|c|c|c|c|c|}
\hline \multirow{2}{*}{\multicolumn{3}{|c|}{ Patient No. }} & \multicolumn{2}{|c|}{ Chewing } & \multicolumn{2}{|c|}{ Retention } & \multicolumn{2}{|c|}{ Confidence } & \multicolumn{2}{|c|}{ Comfort } & \multicolumn{2}{|c|}{ Speaking } \\
\hline & & & I & D & I & D & I & $\mathrm{D}$ & I & D & I & D \\
\hline \multirow{4}{*}{$\begin{array}{c}\text { Kin } \\
\text { oro }\end{array}$} & \multicolumn{2}{|c|}{ Mean } & 2.66 & 2.33 & 3 & 2.33 & 2.66 & 2.66 & 3 & 2.33 & 2.66 & 2 \\
\hline & & 1 & $0 \%$ & $0 \%$ & $0 \%$ & $0 \%$ & $0 \%$ & $0 \%$ & $0 \%$ & $0 \%$ & $0 \%$ & $0 \%$ \\
\hline & Index & 2 & $33.3 \%$ & $66.7 \%$ & $0 \%$ & $66.7 \%$ & $33.3 \%$ & $33.3 \%$ & $0 \%$ & $66.7 \%$ & $33.3 \%$ & $100 \%$ \\
\hline & & 3 & $66.7 \%$ & $33.3 \%$ & $100 \%$ & $33.3 \%$ & $66.7 \%$ & $66.7 \%$ & $100 \%$ & $33.3 \%$ & $66.7 \%$ & $0 \%$ \\
\hline \multirow{4}{*}{$\begin{array}{c}\text { Bony } \\
\text { plus }\end{array}$} & \multicolumn{2}{|c|}{ Mean } & 3 & 2.66 & 2.66 & 2.66 & 2.66 & 2.66 & 2.33 & 2 & 3 & 3 \\
\hline & \multirow{3}{*}{ Index } & 1 & $0 \%$ & $0 \%$ & $0 \%$ & $0 \%$ & $0 \%$ & $0 \%$ & $0 \%$ & $0 \%$ & $0 \%$ & $0 \%$ \\
\hline & & 2 & $0 \%$ & $33.3 \%$ & $33.3 \%$ & $33.3 \%$ & $33.3 \%$ & $33.3 \%$ & $66.7 \%$ & $100 \%$ & $0 \%$ & $0 \%$ \\
\hline & & 3 & $100 \%$ & $66.7 \%$ & $66.7 \%$ & $66.7 \%$ & $66.7 \%$ & $66.7 \%$ & $33.3 \%$ & $0 \%$ & $100 \%$ & $100 \%$ \\
\hline
\end{tabular}

$1=$ less. $2=$ same. $3=$ better

$I^{*}:$ Instant patient perception. D**: Delay patient perception

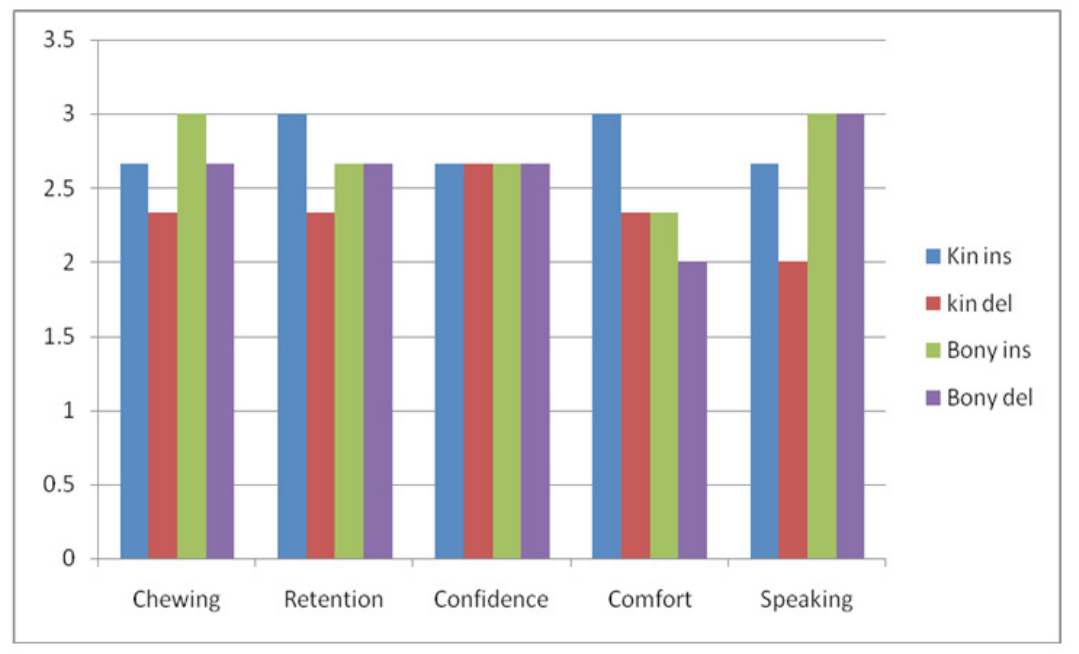

Figure (6) : The mean and frequency of patient perception of Kin oro and Bony plus denture adhesives.

About delayed perception (after 12 hours) there was an improvement in chewing and mastication, retention and fitness for Bony plus adhesive $66.7 \%$, but not with Kin oro adhesive $33.3 \%$, while there was an improvement in confidence $66.7 \%$ for both types of adhesives, while there was no improvement in comfort for both types (Kin oro adhesive $33.3 \%$, Bony plus adhesive $0 \%$ ), Finally, there was an improvement in speaking only for Bony plus adhesive $100 \%$ but for Kin oro adhesive $0 \%$.

\section{DISCUSSION}

There are several factors that account for retention of complete dentures, including adhesion, cohesion, interfacial surface tension, capillary action, atmospheric tension, and oral/facial musculature. ${ }^{(17)}$ Not all of these factors act at the same time; instead, some act only when needed to meet or resist a certain dislodging force. These factors, along with the appropriate fabrication of the complete denture, combine to retain the prosthesis.

The denture adhesives are mainly used to improve fit, comfort, chewing ability and confidence of the patient. The availability of different types of adhesives necessitates their quantitative and in vivo assessments, to aid in the selection of adhesive. The present study showed a statistically significant increase in incisal bite force of the complete denture patients after application of denture adhesives, this results were agreed with other studies which showed significant increase in incisal bite force up to 6 hours ${ }^{(9)}$. and 8 hours after adhesive application. ${ }^{(18)}$ Bony plus denture adhesive was found to be more effective than Kin oro adhesive. 
When evaluating the effect of denture adhesive subjectively, all of the patients agreed that the denture adhesive improved their comfort level and ease of eating. These results were also supported by and Psillakis et al., ${ }^{(2)}$ and Kulak et al., ${ }^{(19)}$ found that most patients were satisfied with the performance of their dentures with denture adhesive application. The masticatory performance as well as retention and stability of dentures improved significantly.

\section{CONCLUSIONS}

It was concluded that the use of denture adhesive significantly effective in improving the incisal bite force of complete dentures until the dislodgement of upper denture. Bony plus paste adhesive was found to be more effective than Kin oro paste. Subjectively, the patients reported an improved perception of denture performance and that the use of adhesive provided greater confidence when using the prosthesis.

\section{REFERENCES}

1. Panagiotouni E, Pissiotis A, Kapari D, A Kaloyannides,. Retentive ability of various denture adhesive materials: An in vitro study. J Prosthet Dent.1995;73:578-585.

2. Psillakis J, Wright R, Grbic J, Lamster I,. In Practice Evaluation of a Denture Adhesive Using a Gnathometer. J Prosthodont. 2004;13(4): 244-250.

3. 3- Kasperski J, Chladek G, Żmudzki J, Lipski T,. The effect of saturation by artificial saliva on the effectiveness of denture adhesives. Arch. Mat. Sceni. Eng. 2011;51(1):25-32.

4. Chew C,. Retention of denture adhesives - an in vitro Study. J Oral Rehabil.1990;17:425-434.

5. Rendell J, Grasso J, Gay T,. Retention and stability of the maxillary denture during function. J Prosthet Dent.1995; 73: 344-347.

6. Hasegawa S, Sekita T, Hayakawa I,. Effect of denture adhesive on stability of complete dentures and the masticatory function. J Med Dent Sci.2003;50:239-247.

7. Mañes J, Selva E, De-Barutell A, Bouazza $\mathrm{K}$,. Comparison of the retention strengths of three complete denture adhesives: an in vivo study.Med Oral Patol Oral Cir Bucal.2011;16(1):132-136.

8. Munoz C, Gendreau L, Shanga G, Magnuszewski T, Fernandez P, John
Durocher J,. A Clinical Study to Evaluate Denture Adhesive Use in Well-Fitting Dentures. J Prosthodont.2012;21: 123-129.

9. Ozcan M, Kulak Y, Baat C, Arikan A, Ucankale M,. The Effect of a New Denture Adhesive on Bite Force Until Denture Dislodgement. J Prosthodont.2005; 14:122-126.

10. Baat C, Hof M, Zeghbroeck L, Özcan M, Kalk W,. An international multicenter study on the effectiveness of a denture adhesive in maxillary dentures using disposable gnathometers. Clin Oral Invest. 2007; 11:237-243.

11. Hong G, Maeda T, Hamada T,. The effect of denture adhesive on bite force until denture dislodgment using a gnathometer. Int Chin J Dent.2010;10:40-45.

12. Tarib N, Bakar M, Murat M, Ahmad M, Kamarudin K, Masticatory efficacy and bite force in complete dentures: a study of denture adhesive. Hong Kong Dent J.2010;7:67-73.

13. Wang Y, Chen Y,. Adhesive-mediated enhancement of occlusal force measurements in patients with existing and new complete dentures: a pilot study. Int J Prosthodont. 2010;23(2):155-157.

14. Pradies G, Sanz Ignacio, Evans Ofelia, Martinez F, Mariano S., Clinical Study Comparing the Efficacy of Two Denture Adhesives in Complete Denture Patients. Int J Prosthodont. 2009;22:361-367.

15. Polyzois G, Lagouvardos P, Frangou M, Stefaniotis T,. Efficacy of denture adhesives in maxillary dentures using gnathodynamometry: a comparative study. Odontology.2011; 99(2):155-161.

16. Kalra P, Nadiger R, Shah F,. An investigation into the effect of denture adhesives on incisal bite force of complete denture wearers using pressure transducers - a clinical study. J Adv Prosthodont.2012;4(2):97-102.

17. Zarb G, Boucher C,. Boucher's prosthodontic treatment for edentulous patients, 10th ed,1990;S t. Louis, MO, Mosby, P:507.

18. Grasso J, Rendell J, Gay T,. Effect of denture adhesive on the retention and stability of maxillary dentures. J Prosthet Dent. 1994; 72: 399-405.

19. Kulak Y, Ozcan M, Arikan A,. Subjective assessment by patients of the efficiency of two denture adhesive pastes, J Prosthodont.2005;14:248-252. 